\title{
Г.Н. Алишина
}

\section{НЕМЦЫ ТОМСКА В КОНЦЕ ХІХ - НАЧАЛЕ ХХ в.: «НЕМЕЦКИЙ СЛЕД» В ПРОСТРАНСТВЕ ГОРОДА}

\author{
Исследование выполнено в рамках работ по проекту «Человек в меняющемся мире. Проблемы идентичности \\ и социильной адаптации в истории и современности» (грант Правительства РФ П 220 № 14.В25.31.0009).
}

\begin{abstract}
Рассматривается немецкое население г. Томска в конце XIX - начале XX в.: сферы деятельности, институциональное оформление лютеранской общины. Особое внимание уделяется манифестации немецкой этничности в городском пространстве, нашедшей свое отражение в названиях коммерческих заведений и их продукции, объявлениях и прочих информационных сообщениях в местной прессе, городской топонимике. Затронут вопрос о влиянии Первой мировой войны и развернувшейся в связи с ней антинемецкой кампании на манифестацию томскими немцами своей этничности.

Ключевые слова: город; лютеране; немцы; Томск; этнизация.
\end{abstract}

Различные аспекты проблемы этничности в условиях города не обделены вниманием ученых. Среди удачных попыток обращения к этой проблеме можно выделить коллективную монографию «Переселенческое общество Азиатской России: миграции, пространства, сообщества», где одна из глав полностью посвящена этнизации городского пространства [1. С. 211296]. Коллективу авторов удалось, опираясь на конкретные примеры, обобщить наблюдения и выводы о проблеме этнизации. В данной статье использовано предложенное ими определение этнизации как процесса манифестации этничности, выхода ее в публичную сферу, а также выделенные ими причины или условия, когда в городе происходит актуализация этничности (урбанизация, конфликты, сознательная деятельность властей и т.д.).

Для рассмотрения в историческом ключе проблемы этнизации городского пространства прекрасно подходят сибирские города конца XIX - начала XX в. Их население имело сложный сословный, национальный и конфессиональный состав. В пореформенный период главную роль в пополнении городского населения за Уралом играл механический прирост [2. С. 15]. Города испытывали постоянный приток населения извне, что обеспечивало быстрый рост числа жителей. Томск в этом плане не был исключением. По данным переписи 1897 г., пришлое население города составляло 67,6\% [Там же. С. 15-16]. В числе «новых томичей» были и недавние сельские жители, и горожане. Формировалось и этническое многообразие. Среди национальных групп неместного происхождения наибольшее значение имели евреи, поляки и немцы. Складывание томского городского сообщества в рассматриваемый период происходило на фоне обретения городом нового статуса (университетского центра), развития торговли и промышленности, мировоззренческих сдвигов, спровоцированных модернизационными процессами в стране, зарождения элементов гражданского общества.
Все это стало благодатной почвой для актуализации этничности, когда этнический фактор увеличивает свою роль в жизни городского сообщества. Этому могли способствовать также и урбанизация, наводнившая Томск сельскими жителями, и приток трансграничных мигрантов, и смена городом своей функции. В данной работе этнизация городского пространства будет рассмотрена на примере немецкого населения Томска в конце XIX - начале XX в., включая годы Первой мировой войны, оказавшей на этот процесс заметное влияние.

В городах имперской Сибири немцы никогда не были многочисленны. Обычно в перечне этнических групп, распределенных по численности, они занимали одно из последних мест. В Томске немцев также было немного. Поскольку учет населения в то время велся по конфессиональной принадлежности, для определения их числа приходится обращаться к данным о численности лютеран. Такой подход, безусловно, не может считаться точным. Однако в случае с Томском он вполне оправдан, поскольку, согласно источникам, томские лютеране в подавляющем большинстве были немцами (таблица) [3. С. 124].

\section{Численность лютеран в г. Томске в конце XIX - начале XX в. ${ }^{1}$}

\begin{tabular}{|c|c|c|c|}
\hline Год & Мужчины & Женщины & Всего \\
\hline 1895 & 344 & 273 & 617 \\
\hline 1901 & 626 & 444 & 1070 \\
\hline 1909 & 613 & 427 & 1040 \\
\hline
\end{tabular}

Превалирование конфессиональной идентичности над этнической было характерно не только для учета населения. В обществе в целом также господствовал этот подход, что, однако, не исключало этнического самосознания (особенно это касалось меньшинств). Насколько тонкой была грань между этническим и конфессиональным, можно увидеть на примере того, что идея создать «немецкий клуб» родилась на лютеранском музыкально-танцевальном вечере, «на кото- 
ром собралось почти все лютеранское общество г. Томска» [7. 28 янв.].

Интенсивное экономическое развитие региона требовало привлечения разного рода специалистов, которых среди местного населения попросту не было. Немцы были среди тех, кто пришел в Сибирь для утоления «кадрового голода». Ими укомплектовывался штат чиновников, а также специалистов губернских, областных и уездных управлений. За XIX - начало $\mathrm{XX}$ в. в Томской губернии было только семь гражданских губернаторов немецкого происхождения. Много немцев занималось преподавательской и научной деятельностью, являясь сотрудниками Томского императорского университета, Технологического института и других учебных заведений. Была среди немцев Томска и прослойка предпринимателей. Достаточно вспомнить пивоваренный завод Крюгера, колбасную и консервную фабрику Фильберта, кондитерские и булочные Грениха, магазин музыкальных товаров Шмидта и др.

Томское немецко-лютеранское сообщество было достаточно консолидированным. Скрепляющим его «цементом» являлась религия. Еще в 1847 г. в Томске был создан Церковный совет лютеранской общины [8. С. 24]. В 1864 г., наконец, завершилось строительство лютеранского храма, который был назван в честь Св. Марии [3. С. 123]. В 1889 г. рядом с кирхой на средства Вспомогательной кассы лютеран началось строительство пастората [9. С. 218], а в 1890 г. пастор окончательно перебрался из Барнаула в Томск [Там же]. Было и свое кладбище, находившееся по соседству с православным Преображенским и магометанским кладбищами [10. С. 32]. Рядом с ним в 1896 г. была заложена часовня [11. С. 234]. Постепенно лютеранская община начала обрастать другими институтами. 13 ноября 1896 г. распахнуло свои двери частное начальное училище при Евангелическо-Лютеранской церкви [12. Л. 12]. С 1897 г. при кирхе действовал приют для детей-сирот [13. 29 янв.]. В 1905 г. ${ }^{2}$ было образовано Томское евангелическо-лютеранское дамское благотворительное общество [10. С. 100-101]. Все это свидетельствует об институциональном оформлении немецко-лютеранского сообщества Томска, позволявшем ему сохранять и воспроизводить (недаром часть общинных институтов была нацелена на молодое поколение) свою идентичность в условиях инокультурного окружения.

Отношение к своей этничности (конфессиональности), вернее ее манифестация, имеет у немцев Томска довольно четкий переломный момент, связанный со вступлением Российской империи в Первую мировую войну. До событий 1914 г. томские немцы не только не скрывали свою этничность, они использовали ее как конкурентное преимущество. Наиболее очевидно это проявлялось в предпринимательской деятельности и сфере услуг. И там, и там эпитет «немецкий» (а также близкие ему по значению определения) явно ассоциировался с качеством, добротностью, гарантией и в це- лом с более высоким уровнем предлагаемого товара. Пивоваренный завод Р.И. Крюгера выпускал множество сортов пива, особой популярностью среди которых пользовались «Мюнхенское» и «Баварское» [15. 9 авг.; 16. 20 дек.]. Часто указание на «немецкость» содержалось в самом названии фирмы. Например, «Венское колбасное и гастрономическое заведение А. Фильберт и К», которое в качестве подтверждения «немецкого имиджа» удостоилось золотой медали на промышленной и сельскохозяйственной выставке в Красноярске в 1892 г. [17. С. 99-100]. Заведения и конторы, названные по фамилии владельца, также несли в себе признак «немецкости» и сопутствующий шлейф смыслов, например «Музыкальный магазин В.Ф. Шмидта». В 1902 г. в «Сибирской жизни» появилось объявление об открытии г-жей А. Брейтигам «немецкого пансиона», в котором анонсировалось «особенное внимание на воспитание» [18. 13 авг.].

Судя по всему, среди обеспеченных горожан весьма ценились немецкие репетиторы и прислуга (смотрители, швейцары, гувернантки). Объявления с предложением и, что особенно показательно, спросом на их услуги регулярно появлялись в местной прессе [19. 10 дек.; 20. 2 июня; 21. 8 фев.; 5.18 фев.; 22. 15 мая; 15. 11, 12 окт., 9, 17 ноя., 15 дек. и др.]. Этническая принадлежность в этих объявлениях не только не скрывалась, но, напротив, подчеркивалась.

Конфессиональная принадлежность, которую в рассматриваемом случае можно приравнять к этнической, манифестировалась в пространстве общественной городской жизни. В местной прессе регулярно появлялись объявления от имени томской лютеранской общины, причем как на русском, так и на немецком языках. Объявления, касающиеся только членов общины (например, об очередном собрании прихожан), публиковались на немецком языке [5. 14 фев.; 13. 22 янв., 16 сен., 16 окт.; 21. 5 фев.; 23. 7 фев.; 24. 5 ноя.; 25. 7 фев., 22 сен.; 26. 23 марта, 17 апр.; 27. 13 апр., 16 сен.]. Сообщения, предназначенные для более широкой аудитории (например, об устроении лютеранским обществом какого-либо мероприятия), были на русском [23. 17 апр.]. Встречались объявления сугубо бытового характера (заявление о правах, поиск гувернантки или квартиросъемщиков и др. [13. 18 мая, 10 окт.; 5.18 фев., 28 сен.]) на немецком языке. Можно сказать, что немецкий являлся языком корпоративного общения в среде лютеран г. Томска. Заметим, что немцы были в этом не одиноки, схожим образом использовали свой родной язык и томские поляки.

Остался «лютеранский след» и в городской топонимике. Улица вблизи кирхи, расположенная от Соборной улицы до Офицерской (ныне ул. Белинского) и долгое время остававшаяся безымянной, с 1910 г. стала называться «Лютеранским переулком» [11. С. 234]. Кроме того, в городе было уже упомянутое Лютеранское кладбище.

Такое присутствие «немецкости» в томском городском пространстве свидетельствует о комфортных 
условиях существования немецко-лютеранской общины. Можно утверждать, что к томским немцам местные власти и общественность относились весьма доброжелательно. Во многом это можно объяснить пользой, которую приносили немцы городу, являясь его ценнейшим людским ресурсом. Их вклад в такие важные сферы городской жизни, как управление, образование, предпринимательство, однозначно признавался и перекрывал факт их пришлости, чужеродности, отличности от принимающего общества.

Только в порядке редкого исключения в местной печати правого толка, традиционно выступавшей за искоренение инородческого засилья в стране, промелькивали публикации о потенциальной опасности столь заметного числа немцев среди местного чиновничества. Упор в подобной критике делался на «характерные» для чиновника-немца пороки: пьянство, сладострастие, пренебрежение должностными обязанностями и проч., причиной которых якобы являлось нерусское происхождение [28. 8 фев.]. Но главной «инородческой угрозой» до вступления России в Первую мировую войну считалось все-таки еврейское, а не немецкое население города.

Огромные изменения в ситуацию внесли события 1914 г. Столкновение Российской империи с АвстроВенгрией и Германией стало причиной резкого и сильного всплеска антинемецких настроений в стране. Пропаганда начала усиленно работать над содержанием понятия «немец», превращая позитивные этнические стереотипы в олицетворение враждебности, неблагонадежности, вредительства. Особенно больно эта кампания ударила по немцам столичных городов. Томск в этом плане можно охарактеризовать как благополучный для немцев населенный пункт. Погромов и других видов явных притеснений со стороны местных властей и жителей в источниках не зафиксировано.

Даже местная правая пресса не отличалась усердием по части дискредитации томского немецкого сообщества, публикуя антинемецкие материалы общего характера или перепечатывая их из центральных периодических изданий. За период с августа по декабрь 1914 г. в «Сибирской правде» появились лишь две «местные» антинемецкие публикации: об открытии неким Глейе частной мужской гимназии (с резюме, содержащим уверенность, что «совершенно несвоевременно и неуместно дозволять немцу открывать русское среднеучебное заведение») [Там же. 27 сен.] и сообщение о том, что в кондитерской Грених немецкие военнопленные «находят не только приют и ласку, но и ведут какие-то серьезные переговоры» [Там же. 18 окт.].

Единственным ощутимым последствием смены этнических симпатий в стране стало то, что отличавшая- ся до войны активностью лютеранская община г. Томска практически свела свою публичную общественную деятельность на нет. Из местной прессы почти исчезли объявления самой общины и сообщения о проводимых ею мероприятиях.

Однако религиозная и внутриобщинная жизнь томских лютеран все же продолжалась. Согласно объявлению в томской газете, 15 марта 1915 г. пастором Гессе в лютеранской кирхе было совершено богослужение с причастием и конфирмацией [29. 15 марта]. Не перестали функционировать школа при лютеранском приюте и сам приют. Хоть и не так активно, но попрежнему проявляло себя благотворительное общество дам-лютеранок. Накануне Рождества в конце 1915 г. оно отправило в действующую армию «70 рождественских подарков (белье, рукавицы, чай, сахар, табак и проч.) на сумму около 300 р.» [Там же. 17 дек.]. Тот факт, что институциональная составляющая лютеранской томской общины не понесла потерь и пусть менее активно, но продолжала функционировать, говорит о лояльности в этом вопросе местных властей и общества. Складывается впечатление, что они предпочли не обращать внимание на то обстоятельство, что в городе проживают немцы, поскольку понимали, что гонения в их адрес нарушат баланс томского городского сообщества, а немцы, в свою очередь, стали в куда меньшей степени афишировать свою этничность и конфессиональность, уйдя в этом смысле в «тень».

Пример немцев Томска в конце XIX - начале XX в. показывает, что этнизация городского пространства пришлым элементом воспринимается местным населением не просто спокойно, а даже с симпатией в том случае, если «пришельцы» рассматриваются как носители передового опыта и более высокой культуры. Приносимая ими польза придает их этничности и ее составляющим позитивную коннотацию в глазах принимающего городского сообщества и может расцениваться даже как нечто лучшее относительно этнически родного аналога. Это совпадает с выводами авторов монографии «Переселенческое общество Азиатской России: миграции, пространства, сообщества», также отметивших принципиальную важность пользы, приносимой «пришельцами» городу, и осознания этого обстоятельства горожанами [1. С. 223]. Таким образом, сам факт и степень манифестации этическим меньшинством своей этничности можно расценивать как показатель комфортности его проживания в условиях иноэтничного большинства. В то же время обострение отношений со страной исхода этнического меньшинства может заметно повлиять на восприятие и оценку процесса этнизации, внеся в них иррациональную подоплеку.

\section{ПРИМЕЧАНИЯ}

\footnotetext{
${ }^{1}$ Подсчитано по: [4. 25 янв.; 5.22 фев.; 6. С. 44].

${ }^{2}$ Некоторые исследователи называют иную дату образования Общества - 1892 г. [14. С. 84].
} 


\section{ЛИТЕРАТУРА}

1. Переселенческое общество Азиатской России: миграции, пространства, сообщества / науч. ред. В.И. Дятлов, К.В. Григоричев. Иркутск : Оттиск, 2013. 624 с.

2. Скубневский В.A. Урбанизационные процессы в Сибири второй половины ХІХ - начала ХХ в. : избранные статьи. Барнаул, 2010.296 с.

3. Памятная книжка Томской губернии на 1908 год.210+56+80 c.

4. Томский справочный листок. Томск, 1895.

5. Сибирская жизнь (Томск). 1901.

6. Кутилова Л.А., Нам И.В., Наумова Н.И., Сафонов В.А. Национальные меньшинства Томкой губернии. Хроника общественной и культурной жизни. 1885-1919. Томск, 1999. 298 с.

7. Сибирская жизнь (Томск). 1911.

8. Караваева А.Г. Кирха Святой Марии // Томск magazine. 2005. № 4. С. 24-26.

9. Черказьянова И.В. Организация духовной жизни лютеран в Сибири: хроника событий (XVIII в. - 1919 г.) // Известия Омского городского историко-краеведческого музея. 2000. № 8. С. 207-226.

10. Адресно-справочная книжка «Весь Томск» на 1912-1913 гг. Томск, 1912. 24+9+332+21 с.

11. Пашкова Н.В., Рейно Л.А. Из истории лютеранской общины г. Томска // Немцы Сибири: история и культура. Омск, 2002. С. $234-236$.

12. Государственный архив Томской области. Ф. 126. Оп. 1. Д. 920.

13. Сибирская жизнь (Томск). 1899.

14. Черказьянова И.В. Школьное образование российских немцев (проблемы развития и сохранения немецкой школы в Сибири в XVIIIХХ вв.). СПб., 2004. $368 \mathrm{c.}$

15. Сибирская жизнь (Томск). 1906.

16. Сибирская мысль (Томск). 1906.

17. Томск. История города от основания до наших дней / отв. ред. Н.М. Дмитриенко. 2-е изд., испр. и доп. Томск, 2004. 464 с.

18. Сибирская жизнь (Томск). 1902.

19. Томский справочный листок (Томск). 1894.

20. Томский справочный листок (Томск). 1895.

21. Сибирская жизнь (Томск). 1900.

22. Сибирская жизнь (Томск). 1908

23. Томский листок (Томск). 1897.

24. Сибирская жизнь (Томск). 1897.

25. Сибирская жизнь (Томск). 1898.

26. Сибирская жизнь (Томск). 1903.

27. Сибирская жизнь (Томск). 1904.

28. Сибирская правда (Томск). 1914.

29. Сибирская жизнь (Томск). 1915.

Alishina Galina N. Tomsk State University (Tomsk, Russian Federation). E-mail: galinaalishina@gmail.com GERMANS IN TOMSK IN THE END OF THE $19^{\mathrm{TH}}$ TO THE EARLY $20^{\mathrm{TH}}$ CENTURY: THE 'GERMAN TRACE' IN THE CITY SPACE.

Keywords: city; Lutherans; Germans; Tomsk; ethnicization.

The article deals with the German population of the city of Tomsk in the late $19^{\text {th }}$ to the early $20^{\text {th }}$ century. It indicates that the Germans here were active in such areas as management, education, commerce, services, and other. The article also explores the institutional formation of their community which was based on the religious affiliation of the majority of the Germans in Tomsk - Lutheranism. In particular, during that period there were Lutheran church, school, charity-school, and a female charity society established in Tomsk. Special attention is paid to the ethnicization, i.e. the manifestation of German ethnicity in the city space. The German ethnicity is reflected in the names of commercial enterprises and their products, advertisements and news reports in the local press, as well as in city»s toponyms. Such presence of «Germanness» in the Tomsk city space, according to the author, indicates that the German Lutheran community enjoyed a comfortable position here and that the Germans were treated well by the local authorities and the general public. This can largely be explained by the contribution that they made to the city, constituting its most valuable human resource. The events of 1914 introduced certain changes to the situation. The clash of the Russian Empire with Austria-Hungary and Germany led to a rapid upsurge of anti-German sentiment in the country. The propaganda began to work hard on the concept of «German», turning positive ethnic stereotypes into the personification of hostility, disloyalty, and sabotage. The unfolded anti-German campaign hit hardest the Germans living in capital cities. Tomsk, in this regard, can be characterized as a favourable one to live in for the Germans. There is no evidence of German pogroms and other forms of overt harassment on the part of the local authorities or residents indicated in the sources. The only notable consequence of the change of ethnic sentiments in the country was that being previously very active, now the Lutheran community of Tomsk almost nullified its public activity. The Tomsk Germans started to advertise their ethnicity to a much lesser degree, trying to keep a low profile. The case of the Germans of Tomsk in the late $19^{\text {th }}$ to the early $20^{\text {th }}$ century shows that the ethnicization of the urban space by the «alien element» was taken not just calmly but with sympathy by the local population as the «aliens» were considered to bring excellence and high culture. Thus, positive connotations were associated with this ethnicity and its manifestations within the host city society. At the same time, the case in question allows us to note that such an external factor as the worsening of relations with the country of origin of an ethnic minority can significantly affect the perception and evaluation of the ethnicization process.

\section{REFERENCES}

1. Dyatlov, V.I. \& Grigorichev, K.V. (eds) (2013) Pereselencheskoe obshchestvo Aziatskoy Rossii: migratsii, prostranstva, soobshchestva [Resettlement Society of Asian Russia: migration space community]. Irkutsk: Ottisk.

2. Skubnevskiy, V.A. (2010) Urbanizatsionnye protsessy $v$ Sibiri vtoroy poloviny $X I X-$ nachala XX $v$. [Urbanization processes in Siberia in the late $19^{\text {th }}-$ early 20th centuries]. Barnaul.

3. Anon. (1908) Pamyatnaya knizhka Tomskoy gubernii na 1908 god [The memorial book of the Tomsk province in 1908]. Tomsk: S. Yakovlev Typography.

4. Tomskiy spravochnyy listok. (1895) Tomsk.

5. Sibirskaya zhizn' (1901) Tomsk 
6. Kutilova, L.A., Nam, I.V., Naumova, N.I. \& Safonov, V.A. (1999) Natsional'nye men'shinstva Tomkoy gubernii. Khronika obshchestvennoy $i$ kul'turnoy zhizni. 1885-1919 [National minorities of Tomks province. The chronicle of social and cultural life. 1885-1919]. Tomsk: Tomsk State Universuty.

7. Sibirskaya zhizn' (1911) Tomsk.

8. Karavaeva, A.G. (2005) Kirkha Svyatoy Marii [St. Mary Catholic Church]. Tomsk magazine. 4. pp. 24-26.

9. Cherkaz'yanova, I.V. (2000) Organizatsiya dukhovnoy zhizni lyuteran v Sibiri: khronika sobytiy (XVIII v. - 1919 g.) [The organization of the spiritual life of Lutherans in Siberia: The chronicle (the 18th century - 1919)]. Izvestiya Omskogo gorodskogo istoriko-kraevedcheskogo muzeya. 8. pp. 207226.

10. Anon. (1912) Adresno-spravochnaya knizhka "Ves' Tomsk" na 1912-1913 gg. [Address and Reference Book “The Whole Tomsk” for 1912-1913]. Tomsk.

11. Pashkova, N.V. \& Reyno, L.A. (2002) Iz istorii lyuteranskoy obshchiny g. Tomska [From the history of the Tomsk Lutheran community]. In: Nemtsy Sibiri: istoriya i kul'tura [Germans of Siberia: history and culture]. Omsk. pp. 234-236.

12. The State Archives of Tomsk Region (GATO). Fund 126. List 1. File 920.

13. Sibirskaya zhizn' (1899) Tomsk

14. Cherkaz'yanova, I.V. (2004) Shkol'noe obrazovanie rossiyskikh nemtsev (problemy razvitiya i sokhraneniya nemetskoy shkoly v Sibiri v XVIII-XX vv.) [School education of the Russian Germans (the problems of development and the preservation of the German school in Siberia in the 18th - 20th centuries)]. St. Petersburg: Public Academy of Sciences of Russian Germans.

15. Sibirskaya zhizn' (1906) Tomsk.

16. Sibirskaya mysl' (1906) Tomsk.

17. Dmitrienko, N.M. (2004) Tomsk. Istoriya goroda ot osnovaniya do nashikh dney [Tomsk. The history of the city from the foundation to the present day]. 2nd ed. Tomsk: Tomsk State University.

18. Sibirskaya zhizn' (1902) Tomsk.

19. Tomskiy spravochnyy listok (1894) Tomsk.

20. Tomskiy spravochnyy listok (1895) Tomsk.

21. Sibirskaya zhizn' (1900) Tomsk.

22. Sibirskaya zhizn' (1908) Tomsk.

23. Tomskiy listok. (1897) Tomsk.

24. Sibirskaya zhizn' (1897) Tomsk

25. Sibirskaya zhizn' (1898) Tomsk.

26. Sibirskaya zhizn' (1903) Tomsk

27. Sibirskaya zhizn' (1904) Tomsk.

28. Sibirskaya pravda (1914) Tomsk.

29. Sibirskaya zhizn' (1915) Tomsk. 